of interference the perimetric evidence at present available indicates the optic tract rather than a temporal detour of the geniculo-calcarine fibres.

\title{
REFERENCES
}

1. Henschen.- " Handbuch der Neurologie." Lewandowsky, Berlin, 1910, Vol. I, p. 903-914, Vol. III, p. 773 et seq.

2. Meyer, A. - The connections of the Occipital Lobes and the present status of the Cerebral Visual Affections." Trans. of the Assoc. of Amer. Physicians, 1907, Vol. XXII, p. 7.

3. Idem.-American Neurological Association, 1911.

4. Cushing.- "The Field Defects produced by Temporal Lobe Lesions." Trans. Amer. Neurol. Soc., 1921, and Brain, Vol. XLIV, p. 341. 1921.

5. Cushing and Heuer.- "Distortions of the Visual Fields in Cases of Brain Tumour." Johns Hopkins Hosp. Bulletin, June, 1911, Vol. XXII, p, 190.

6. Discussion on Professor Cushing's paper on "The Field Defects of Temporal Lobe Lesions." Trans. Amer. Neurol. Assoc., June, 1921.

7. Wilbrand and Saenger.- "Die Neurologie des Auges," 1917, Vol. VII, p. 152, et seq.

8. Roenne. - "Ueber die Inkongruenz und Asymmetrie im homonym hemianopischen Gesichtsfeld." Klin. Monatsbl.f. Augenheilk., 1915, Vol. LIV, p. 399.

9. Schirmer.-"A Case of Incongruous Homonymous Hemianopsia." "Arch. of Ophthal., 1912, No. 2, Vol. XLI, p. 136.

10. Walker and Cushing.- "Chiasmal Lesions with especial reference to Homonymous Hemianopsia with Hypophyseal Tumour." Arch. of Ophthal., 1918, No. 2, Vol. XLVII, p. 124.

\section{A CASE OF QUININE AMBLYOPIA BY}
H. GAINSBOROUGH,
AND
R. GainsBOROUGH,
M.B., B.Ch.Cantab.
L.R.C.P., M.R.C.S.

MEDICAL REGISTRAR, ST. GEORGE'S HOSPITAL

A. C., age 41, a chauffeur, was discharged from his employment. At 3 a.m. one morning soon after, while under the influence of drink, he swallowed the remaining contents of a bottle of 5 grain quinine tablets, taking probably about 60 grains. He thought he had a malarial relapse, but he had not had such for a long time, and this was the first dose of quinine he had taken for three years. Possibly there was suicidal intent. He fell asleep again, but a few hours later awakened, feeling considerable distress and giddiness, and within three hours he had lost his sight. $\mathrm{He}$ had considerable nausea and vomited slightly, but there were no subjective auditory sensations.

On examination by one of us (R. G.) eight hours after he had taken the drug, he was found lying in bed; the respiration was quick and shallow, but his colour fairly good; the pulse was rapid, thready and irregular, and the rate was 120 . His sight was gone, he being only just able to distinguish light from dark, but not being able to point to the direction of the light. The pupils were fixed and dilated. The fundi were pale and hazy, the arteries much 
contracted and the discs pale. There was no deafness and no tinnitus, and though he said he was giddy on sitting up, there was no true aural vertigo.

He was sent up to hospital immediately, and on admission was given amyl nitrite inhalation and sodium nitrite gr. ij. Mr. R. R. James saw him two hours later and reported, "The arteries are normal. L.O.D. slight pallor inner side; R.O.D. normal. Pupils mid-dilated ; right flickers to strong light, left inactive to light."

Recovery was very rapid. In the evening he could distinguish windows, shadows, etc., and by the following morning his sight was apparently normal. Two days after taking the quinine his visual fields showed no contraction, and his fundi were normal. Nor was his sight in any way deficient two months later.

The Wassermann reaction was negative.

The taking of quinine was confirmed by finding it in the urine.

The interesting features of this case were the absence of auditory symptoms and the complete recovery so soon after treatment by the nitrites.

We are indebted to Dr. F. Golla and to Mr. R. R. James for permission to publish this case.

\section{AN UNUSUAL CASE OF PERFORATING WOUND OF THE CORNEA}

BY

Charles Killick, M.D., F.R.C.S.

HON. OPHTHALMIC SURGEON, ROYAL EYE AND EAR HOSPITAL, BRADFORD

Mrs. B., age 31, was mending the fire on January 27,1921 , when, through some mishap, the poker slipped and fractured the left lens of her spectacles. Realising that something serious had happened to her left eye she at once saw Dr. Shaw, of Cleckheaton, who sent her to see me without delay.

On examination two separate perforating wounds of the cornea were present; the one lacerated, situated in the two o'clock position, was in the form of a triangular flap of cornea attached by its base to the limbus and extending into the cornea downwards and slightly outwards for about three millimetres. This tongueshaped flap was freely movable, projected above the corneal surface and looked much like a fragment of glass; the iris was freely exposed, but was not protruding from the wound. The second perforation was exactly opposite the first, and was placed at the inferior margin of the cornea, it traversed the limbus at right angles for about two millimetres and was occupied by prolapsed iris. Fortunately the ciliary.body, lens and vitreous were intact. As a 